Article

\title{
Antibiotic Resistance and Extended-Spectrum Beta-Lactamase Production of Escherichia coli Isolated from Irrigation Waters in Selected Urban Farms in Metro Manila, Philippines
}

\author{
Pierangeli G. Vital ${ }^{1,2, *}$, Enrico S. Zara ${ }^{1}$, Cielo Emar M. Paraoan ${ }^{1}$, Ma. Angela Z. Dimasupil ${ }^{1}$, \\ Joseth Jermaine M. Abello ${ }^{1}$, Iñigo Teodoro G. Santos ${ }^{1}$ and Windell L. Rivera ${ }^{1,2}$ \\ 1 Institute of Biology, College of Science, University of the Philippines Diliman, Quezon City 1101, Philippines; \\ enrico.s.zara@gmail.com (E.S.Z.); paraoan_cielo@yahoo.com (C.E.M.P.); \\ angela.dimasupil@gmail.com (M.A.Z.D.); josethabello08@gmail.com (J.J.M.A.); \\ itgsantos@yahoo.com.ph (I.T.G.S.); wlrivera@gmail.com (W.L.R.) \\ 2 Natural Sciences Research Institute, University of the Philippines Diliman, Quezon City 1101, Philippines \\ * Correspondence: pierangeli.vital@upd.edu.ph or piervital@hotmail.com
}

Received: 31 January 2018; Accepted: 20 April 2018; Published: 25 April 2018

check for updates

\begin{abstract}
Highly-polluted surface waters are increasingly used for irrigation in different agricultural settings because they have high nutrient content and are readily available. However, studies showed that they are reservoirs for the emergence and dissemination of antibiotic-resistant bacteria in the environment. In this study, the resistance of 212 Escherichia coli isolates from irrigation water, soil, and vegetables in selected urban farms in Metro Manila, Philippines was evaluated. Results showed that antibiotic resistance was more prevalent in water $(67.3 \%)$ compared to soil $(56.4 \%)$ and vegetable $(61.5 \%)$ isolates. Resistance to tetracycline was the highest among water $(45.6 \%)$ and vegetable $(42.3 \%)$ isolates while ampicillin resistance was the highest among soil isolates (33.3\%). Multidrug-resistant (MDR) isolates were also observed and they were more prevalent in water (25.3\%) compared to soil $(2.8 \%)$ and vegetable $(8.4 \%)$ isolates. Interestingly, there are patterns of antibiotic resistance that were common to isolates from different samples. Extended-spectrum beta-lactamase production (ESBL) was also investigated and genes were observed to be present in 13 isolates. This provides circumstantial evidence that highly-polluted surface waters harbor antibiotic-resistant and MDR E. coli that may be potentially transferred to primary production environments during their application for irrigation purposes.
\end{abstract}

Keywords: antibiotic resistance; ESBL; Escherichia coli; irrigation water; gastrointestinal infections

\section{Introduction}

Agricultural productivity heavily relies on the use of irrigation water in irrigating agricultural plants, applying fertilizers and pesticides, and processing of farm products. In urban agricultural areas where there is limited water supply and high demand for clean water, irrigation water is usually sourced from surface waters contaminated with agricultural runoff, livestock and wildlife fecal material, wastewater discharge, and septic leakage [1,2]. Although surface waters are practical to use because of their availability and high nutrient content, they can be a potential source of fecal contaminants and pathogenic microorganisms that may be transferred to farm products, such as fresh produce, during irrigation [1-3].

The problem of microbial contamination of fresh produce is often compounded by the emergence of antibiotic resistance among pathogenic microorganisms. Antibiotic resistance is caused by 
the widespread and increasing use of antibiotics [4-6] and it is increasingly becoming a global health concern because it limits the available therapeutic options, resulting in higher treatment and hospitalization costs and increased rates of mortality and morbidity [7-9]. A principal method by which bacteria resist antibiotics is through the production of $\beta$-lactamases, enzymes that hydrolyze $\beta$-lactam antibiotics. $\beta$-lactam antibiotics are the most commonly-used antibiotics, including penicillins, cephalosporins, and carbapenems. One group of $\beta$-lactamase enzymes, the extended spectrum $\beta$-lactamases (ESBLs), produced by Escherichia coli, is of particular significance. These are able to target a wider range of antibiotics and plasmids that contain genes for ESBLs which often carry genes for resistance to various other antibiotics [10-12].

Surface waters have been considered as an important source of microbial antibiotic resistance [13-15]. A considerable fraction of antibiotics used in clinical, agricultural, and household settings usually end up in aquatic environments and serve as regulatory and signaling molecules among bacteria [16-18]. The presence of low concentrations of antibiotics in aquatic environments imposes a selection pressure that promotes antibiotic tolerance and emergence of antibiotic resistance in aquatic bacteria [15]. Therefore, surface waters used for irrigation purposes may serve as pools of antibiotic-resistant bacteria that have profound influence on the microbial quality of primary production environments.

In highly-urbanized and densely-populated areas, such as Metro Manila, Philippines, the use of highly-polluted surface waters for irrigation is widely practiced, especially as urban agriculture is gaining popularity as a tool to increase household income and meet subsistence food needs $[2,19]$. This necessitates the assessment and monitoring of the quality of surface waters used for irrigation.

The present study aims to evaluate the resistance of 212 E. coli isolates from irrigation water, soil, and vegetables in selected urban farms in Metro Manila, Philippines against nine commonly-used antibiotics and to ascertain the patterns of antibiotic resistance among the isolates. Further, the isolates were screened for ESBL production and detection of genes encoding ESBLs to assess one of the mechanisms for antibiotic resistance. This information may be useful to raise awareness on the importance of prevention measures to be taken, and it also alerts for the widespread use of antimicrobials, especially in agricultural sectors.

\section{Materials and Method}

\subsection{Bacterial Isolates}

A total of 212 culture-positive E. coli isolates that were previously collected from irrigation water, soil, and vegetable samples from six urban agricultural farms in Metro Manila, Philippines were used in this study [2]. The farms were small scale urban farms in Quezon City, Marikina City and Pasig City that are situated near residential areas and cultivate different vegetables that are sold in nearby wet markets. The farms were chosen because the irrigation waters used in these farming sites are derived from highly-polluted surface waters.

The isolates were sub-cultured into Tryptic Soy Broth (TSB) (Merck, Darmstadt, Germany) and incubated at $35{ }^{\circ} \mathrm{C}$ for $24 \mathrm{~h}$, after which $20 \%$ glycerol was added prior to storage at $-20{ }^{\circ} \mathrm{C}$ for further analysis.

\subsection{Antibiotic Susceptibility Test}

Antibiotic susceptibility testing was patterned after the Antimicrobial Susceptibility Manual of the American Society for Microbiology [20]. In its procedure, pure isolates were sub-cultured into Trypticase Soy Agar (TSA) plates (BD BBL ${ }^{\mathrm{TM}}$, Franklin Lakes, NJ, USA) and incubated at $35^{\circ} \mathrm{C}$ for 16 to $18 \mathrm{~h}$. The isolates were inoculated into $3 \mathrm{~mL} 0.85 \%$ saline solution and the turbidity of the suspension was standardized to that of $0.5 \%$ McFarland standard. Using a sterile cotton swab, the standardized suspension was swabbed and inoculated evenly on the entire surface of Mueller Hinton agar (MHA) plates (Hi-Media Laboratories, India). Then, nine antibiotics which include: tetracycline (30 $\mu \mathrm{g})$, ciprofloxacin $(5 \mu \mathrm{g})$, cefotaxime $(30 \mu \mathrm{g})$, chloramphenicol $(30 \mu \mathrm{g})$, nalidixic acid $(30 \mu \mathrm{g})$, streptomycin 
$(10 \mu \mathrm{g})$, ampicillin $(10 \mu \mathrm{g})$, cephalotin $(30 \mu \mathrm{g})$, and trimethoprim $(30 \mu \mathrm{g})$ were placed on the surface of inoculated MHA plates and incubated at $35^{\circ} \mathrm{C}$ for 16 to $18 \mathrm{~h}$. The antibiotics used in this study were selected as they represent each major class of antibiotics that is used in the treatment of human and animal E. coli infections. Subsequently the clearing zones on the plates were measured using a caliper. The diameters of the clearing zones were interpreted in accordance to the Clinical and Laboratory Standards Institute manual (CLSI) [21]. The test was performed in triplicate and E. coli ATCC®25922 was used as the negative control.

\subsection{Screening for ESBL Production}

Initial screening of E. coli isolates for ESBL production was performed using the disk diffusion method of the CLSI manual [21]. The antibiotics used were ceftazidime (30 $\mu \mathrm{g})$ and cefotaxime $(30 \mu \mathrm{g})$ (BBL Sensi-Disc, BD Diagnostics, MD, USA). Briefly, overnight cultures of the isolates were inoculated into $3 \mathrm{~mL} 0.85 \%$ saline solution and the turbidity of the suspension was adjusted to that of $0.5 \%$ McFarland standard. The suspension was then spread evenly on the entire surface of MHA plates, after which, ceftazidime and cefotaxime disks were placed. After 16 to $18 \mathrm{~h}$ of incubation, inhibition zones were measured and interpreted based CLSI manual [21].

Isolates screened as ESBL producers were subjected to a confirmatory test through the double disk synergy test [12,22]. Suspected ESBL-producing isolates were inoculated into $3 \mathrm{~mL} 0.85 \%$ saline solution to match the turbidity of $0.5 \% \mathrm{McFarland}$ standard. The suspension was spread evenly into MHA plates and ceftazidime and cefotaxime disks were placed 20 to $30 \mathrm{~mm}$ from a disk containing amoxicillin/clavulanic acid $(20 \mu \mathrm{g} / 10 \mu \mathrm{g})$. An increase in zone diameter of $5 \mathrm{~mm}$ or greater for either ceftazidime or cefotaxime, when combined with clavulanic acid, compared with their zone diameters alone, indicated ESBL production by the isolate [23].

\subsection{Detection of ESBL Genes}

ESBL genes were identified from the confirmed ESBL producers through PCR amplification using primers targeting different ESBL genes. Two multiplex sets including Multiplex I TEM, SHV and OXA-1 like, and Multiplex II CTX-M group 1, 2, and 9 were used in this study. Additionally, a simplex set CTX-M group 8/25 was used in this study, following the method of Dallenne et al. [23].

\subsection{Statistical Analysis}

All data were analyzed statistically using Statistical Package for Social Sciences ver. 20.0 (IBM Corp., Armonk, NY, USA). One-way analysis of variance (ANOVA) was used to evaluate significant differences in antibiotic resistance among the isolates recovered from the three different samples. Data that were found to be significant were further analyzed using Tukey's HSD comparison of means and a $p$ value less than 0.05 was accepted as significant. The chi-square test was also employed to compare the frequency of resistance of the isolates from different samples to each antibiotic. Data were considered as statistically significant based on a $p<0.05$.

\section{Results}

\subsection{Antimicrobial Resistance}

A total of 212 culture-positive E. coli consisting of 147 irrigation water, 39 soil, and 26 vegetable isolates were obtained from 190 water, 91 soil, and 92 vegetable samples. The identity of the isolates was confirmed in a previous study [2] using a PCR assay that amplifies the B-glucoronidase (uidA) gene which encodes an acid hydrolase that catalyzes the cleavage of a wide variety of 3-glucuronidases used by of E. coli [24].

The resistance of 212 isolates was tested against nine antibiotics. The percentages of isolates that were susceptible, intermediate and resistant to each antibiotic are presented in Table 1. As shown, there are more antibiotic-resistant isolates from irrigation water compared to soil and vegetables. 
Resistance to tetracycline was the highest among water (45.6\%) and vegetable (42.3\%) isolates, whereas ampicillin resistance was the highest among soil isolates (33.3\%). Meanwhile, resistance to nalidixic acid was the lowest among the water isolates (2.7\%) and resistance to ciprofloxacin (2.6\%) and nalidixic acid $(2.6 \%)$ was the lowest among the soil isolates. Finally, there was no resistance to nalidixic acid and streptomycin observed among the vegetable isolates.

Table 1. Percentages of E. coli isolates from agricultural irrigation water in Metro Manila, Philippines that were susceptible (S), intermediate (I) and resistant (R) to antibiotics. Resistance breakpoints were based on CLSI standards.

\begin{tabular}{|c|c|c|c|c|c|c|c|c|c|c|}
\hline \multirow[t]{2}{*}{ Antibiotic ( $\mu \mathrm{g})$} & \multirow{2}{*}{$\begin{array}{c}\text { Resistance Breakpoint } \\
(\mathrm{mm})\end{array}$} & \multicolumn{3}{|c|}{$\begin{array}{c}\text { Water } \\
n=147\end{array}$} & \multicolumn{3}{|c|}{$\begin{array}{l}\text { Soil } \\
n=39\end{array}$} & \multicolumn{3}{|c|}{$\begin{array}{c}\text { Vegetables } \\
n=26\end{array}$} \\
\hline & & $S$ & I & $\mathbf{R}$ & $\mathrm{S}$ & I & $\mathbf{R}$ & S & $\mathbf{I}$ & $\mathbf{R}$ \\
\hline Ciprofloxacin (5) & $\leq 15$ & 87.1 & 6.1 & 6.8 & 97.4 & 0.0 & 2.6 & 92.3 & 3.8 & 3.8 \\
\hline Cefotaxime (30) & $\leq 22$ & 84.4 & 2.0 & 13.6 & 94.9 & 0.0 & 5.1 & 96.2 & 0.0 & 3.8 \\
\hline Chloramphenicol (30) & $\leq 12$ & 70.7 & 12.9 & 16.3 & 94.9 & 0.0 & 5.1 & 92.3 & 3.8 & 3.8 \\
\hline Streptomycin (10) & $\overline{\leq} 11$ & 77.6 & 9.5 & 12.9 & 87.2 & 5.1 & 7.7 & 88.5 & 11.5 & 0.0 \\
\hline Ampicillin (10) & $\leq 13$ & 66.0 & 0.0 & 34.0 & 64.1 & 2.6 & 33.3 & 65.4 & 0.0 & 34.6 \\
\hline Cephalothin (30) & $\leq 14$ & 70.1 & 20.4 & 9.5 & 76.9 & 10.3 & 12.8 & 65.4 & 23.1 & 11.5 \\
\hline Trimethoprim(30) & $\leq 10$ & 79.6 & 0.0 & 20.4 & 84.6 & 0.0 & 15.4 & 80.8 & 0.0 & 19.2 \\
\hline
\end{tabular}

Overall, the resistance to nine antibiotics was highest among the water isolates (67.3\%) compared to soil $(56.4 \%)$ and vegetable $(61.5 \%)$ isolates. ANOVA revealed that there was significant difference among the antibiotic resistance of isolates from the three different samples $(p=0.008)$. Tukey's HSD, a post hoc analysis showed that the antibiotic resistance of water and vegetable isolates against each antibiotic was significantly different from each other $(p=0.000)$. Comparison of the frequency of resistance of the isolates from different samples to a single antibiotic showed significant differences $(p<0.05)$ for tetracycline, ciprofloxacin, chloramphenicol, nalidixic acid, streptomycin, ampicillin, cephalothin, and trimethoprim. Meanwhile, no significant difference was observed among the frequency of resistance of the isolates from the different samples to cefotaxime $(p=0.075)$.

Among the 212 E. coli isolates, 36.5\% were found to be resistant to at least three antibiotics and were considered as multidrug resistant (MDR). Table 2 summarizes the prevalence of MDR isolates from irrigation water, soil, and vegetables. MDR isolates was more prevalent in water $(25.3 \%)$ compared to soil (2.8\%) and vegetables (8.4\%). Intriguingly, resistance to eight different antibiotics was observed among the water isolates $(0.7 \%)$.

Table 2. Percentages of multidrug resistant E. coli isolates from agricultural irrigation water in Metro Manila, Philippines.

\begin{tabular}{cccc}
\hline $\begin{array}{c}\text { Number of Antibiotics to Which } \\
\text { Isolates are Resistant }\end{array}$ & $\begin{array}{c}\text { Water } \\
\boldsymbol{n = 1 4 7}\end{array}$ & $\begin{array}{c}\text { Soil } \\
\boldsymbol{n}=\mathbf{3 9}\end{array}$ & $\begin{array}{c}\text { Vegetables } \\
\boldsymbol{n}=\mathbf{2 6}\end{array}$ \\
\hline 3 & 10.89 & 0.7 & 7.7 \\
4 & 7.5 & 0.7 & 0.7 \\
5 & 4.8 & 1.4 & 0.0 \\
6 & 1.4 & 0.0 & 0.0 \\
8 & 0.7 & 0.0 & 0.0 \\
Total & 25.3 & 2.8 & 8.4 \\
\hline
\end{tabular}

The patterns of antibiotic resistance among the E. coli isolates were also evaluated in this study. As shown in Table 3, the resistance pattern most prevalent among the isolates is resistance to a combination of tetracycline and ampicillin (2.8\%), followed by resistance to a combination of ampicillin and cephalothin $(2.4 \%)$ and a combination of tetracycline and chloramphenicol $(2.4 \%)$. These antibiotic resistance patterns all occurred among the water isolates. Of the MDR isolates, however, the most 
prevalent pattern is resistance to a combination of ciprofloxacin, chloramphenicol, nalidixic acid, and ampicillin $(2.4 \%)$, and this occurred among water isolates.

Although the patterns of antibiotic resistance greatly differ among water, soil, and vegetable isolates, there were antibiotic resistance patterns that are common to the isolates from different sources. For instance, resistance patterns Amp-Tmp and T-Amp were common to isolates from the three different samples, while resistance patterns Amp-Kf and T-Tmp were common to both water and soil isolates. Lastly, resistance pattern T-Amp-Tmp was common to water and vegetable isolates.

\subsection{Initial Screening for ESBL Production}

Out of 200 E. coli isolates evaluated for possible ESBL production through antimicrobial susceptibility testing with ceftazidime and cefotaxime, 27 isolates tested positive. Thirteen isolates $(16.3 \%)$ were potential or suspected ESBL producers, having zones of $22 \mathrm{~mm}$ or less and $27 \mathrm{~mm}$ or less for ceftazidime and cefotaxime, respectively. This included two of the 48 isolates (4.2\%) from Diliman and 25 of the 32 isolates (34.4\%) from Marikina. Of the potential ESBL producers, one showed resistance and two showed intermediate resistance to ceftazidime, while two showed resistance and nine showed intermediate resistance to cefotaxime.

\subsection{Confirmatory Testing for ESBL Production}

ESBL production was phenotypically confirmed through the double-disk synergy test in 27 (8.75\%) of all E. coli isolates evaluated, as shown in Figure 1. Of the 27 suspected ESBL producers, ESBL production was confirmed in one (1.2\%) of the isolates from Diliman, and in six (18.8\%) of the isolates from Marikina. Molecular testing through PCR amplification of target genes only detected blaTEM, CTX-M groups 1, 2, and 9 and CTX-M group 8/25. Results showed that from the 27 isolates, only 13 were positive for blaTEM, and five and eight isolates for blaCTX-M 1 and 2 respectively. At the same time, no amplicons corresponding to blaSHV-1 and blaOXA were observed.

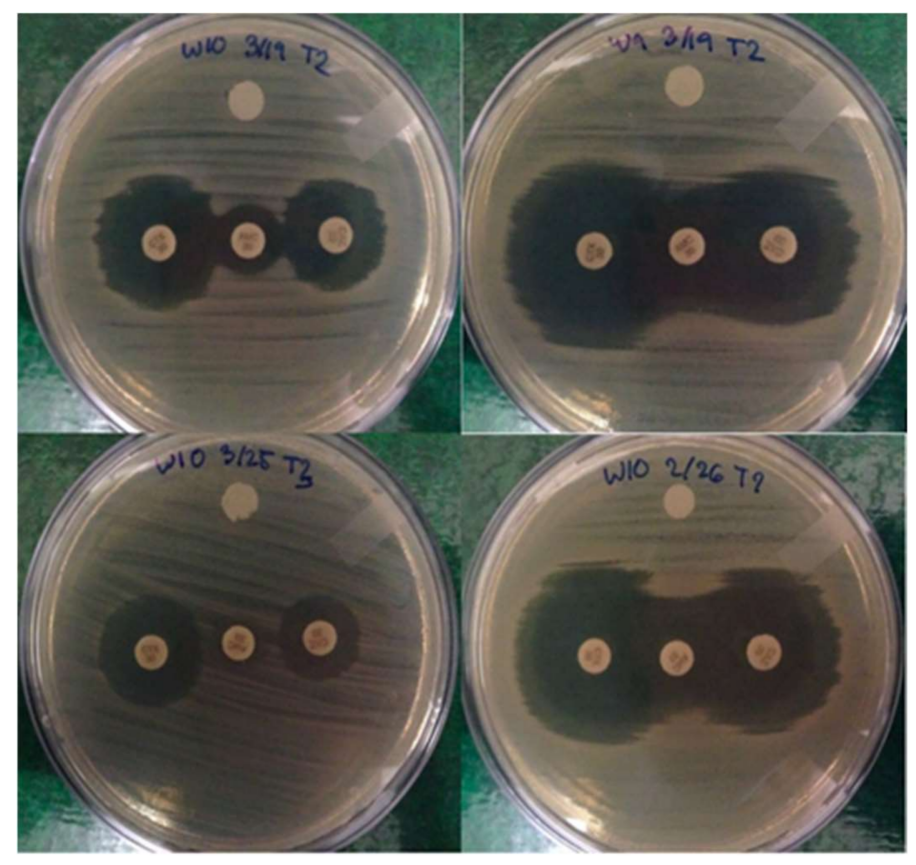

Figure 1. Negative (left) and positive (right) results for confirmatory screening of E. coli isolates from agricultural irrigation waters in Quezon City and Marikina City, Philippines showing zone extension for ESBL-producing isolates. 
Table 3. Antibiotic resistance pattern among E. coli isolates from agricultural irrigation water in Metro Manila, Philippines.

\begin{tabular}{|c|c|c|c|}
\hline Source & $\begin{array}{l}\text { Number of Antibiotic to } \\
\text { Which Isolates Are Resistant }\end{array}$ & Antibiotic Resistance Pattern & Frequency \\
\hline \multirow{11}{*}{$\begin{array}{c}\text { Water } \\
n=147\end{array}$} & 0 & - & 48 \\
\hline & 1 & Amp; Na; S; T; Tmp & $8 ; 3 ; 2 ; 19 ; 3$ \\
\hline & 2 & Amp-Kf; Amp-Tmp; S-Tmp; T-Amp; T-C; T-Na; T-Tmp & $5 ; 3 ; 2 ; 6 ; 5 ; 2 ; 3$ \\
\hline & \multirow{2}{*}{3} & Cip-Na-Amp; Cip-Na-S; S-Amp-Tmp; T-Amp-Kf, T-Amp-Tmp; T-C-Amp; & $1 ; 1 ; 1 ; 2 ; 2 ; 2$ \\
\hline & & T-Cip-Amp; T-C-Na; T-C-Tmp; T-Na-Amp; T-S-Amp & $1 ; 3 ; 1 ; 1 ; 1$ \\
\hline & \multirow{2}{*}{4} & Cip-C-Na-Amp; T-Cip-C-Tmp; T-C-S-Amp; T-Na-Amp-Kf; T-Na-S-Amp; & $1 ; 1 ; 1 ; 1 ; 1 ;$ \\
\hline & & T-Na-S-Tmp; T-S-Amp-Tmp & $1 ; 5$ \\
\hline & \multirow{2}{*}{5} & Na-S-Amp-Kf-Tmp; T-Cip-C-Na-Ctx; T-Cip-C-Na-Tmp; T-Cip-Na-Amp-Kf; & $1 ; 1 ; 1 ; 1 ;$ \\
\hline & & T-C-Na-Amp-Tmp; T-Ctx-Amp-Kf-Tmp; T-S-Amp-Kf-Tmp & $1 ; 1 ; 1$ \\
\hline & \multirow{2}{*}{$\begin{array}{l}6 \\
8\end{array}$} & Cip-Na-Ctx-Amp-Kf-Tmp; T-C-Na-S-Amp-Tmp & $1 ; 1$ \\
\hline & & T-C-Na-Ctx-S-Amp-Kf-Tmp & 1 \\
\hline \multirow{6}{*}{$\begin{array}{c}\text { Soil } \\
n=39\end{array}$} & 0 & - & 17 \\
\hline & 1 & Amp; Ctx; $\mathrm{S} ; \mathrm{T} ; \mathrm{Tmp}$ & $2 ; 1 ; 1 ; 3 ; 1$ \\
\hline & \multirow{2}{*}{2} & Amp-Kf; Amp-Tmp; T-Amp; T-Tmp & $3 ; 1 ; 4 ; 2$ \\
\hline & & T-Cip-Na & 1 \\
\hline & 4 & S-Amp-Kf-Tmp & 1 \\
\hline & 5 & T-C-Amp-Kf-Tmp; T-C-Na-S-Amp & $1 ; 1$ \\
\hline \multirow{5}{*}{$\begin{array}{c}\text { Vegetables } \\
n=26\end{array}$} & 0 & - & 10 \\
\hline & 1 & Kf; T & $1 ; 5$ \\
\hline & 2 & Amp-Tmp; Cip-Na; T-Amp & $2 ; 1 ; 3$ \\
\hline & 3 & Amp-Kf-Tmp; T-Amp-Tmp & $1 ; 2$ \\
\hline & 4 & T-C-Amp-Kf & 1 \\
\hline
\end{tabular}

Key: $\mathrm{T}=$ tetracycline Cip $=$ ciprofloxacin $\mathrm{Ctx}=$ cefotaxime $; \mathrm{C}=$ chloramphenicol; $\mathrm{Na}=$ nalidixic acid $\mathrm{S}=$ streptomycin; Amp $=$ ampicillin; $\mathrm{Kf}=$ cephalothin; Tmp $=$ trimethoprim. 


\section{Discussion}

Several studies have shown that surface waters used for irrigation purposes harbor antibioticresistant bacteria. In this study, results showed that irrigation water contain the highest antibiotic resistant-bacteria, followed by vegetable and soil samples. The higher prevalence of antibiotic-resistant bacteria in irrigation water implies that it harbors a sufficient number of bacteria that may be potentially transferred to the primary production environment such as agricultural soils and vegetables during irrigation. Similar results were observed in numerous studies where irrigation waters from different sources are reported to contain elevated numbers of antibiotic resistant E. coli [25-30]. Among the E. coli isolates from irrigation water used in this study, the highest resistance was observed in tetracycline, followed by resistance to ampicillin. The resistance to these antibiotics was also observed among E. coli isolates from irrigation waters in several studies $[25,26,28]$. The presence of tetracycline-resistant $E$. coli in irrigation waters is particularly disturbing, as tetracycline is widely available and extensively used in developing countries as a first-line drug in the treatment of gastrointestinal infections $[15,25,31]$.

Importantly, MDR E. coli isolates were also observed. Multidrug resistance is defined as resistance of an isolate to antibiotics belonging to at least three different classes of antibiotics [32,33]. In this study, MDR isolates were more prevalent in irrigation water isolates compared to soil and vegetable isolates. Similar results were obtained by Paraoan et al. [30] where 46 E. coli isolates (58.22\%) from the agricultural irrigation waters in Bulacan, Philippines were found to be MDR. Further, the results of this study were in agreement with the results of other studies which documented the presence of MDR E. coli from irrigation waters. For instance, Roe et al. [25] showed that the Rio Grande River, a major source of irrigation water for both the USA and Mexico, harbors MDR E. coli with a prevalence rate of $32 \%$. Another important source of irrigation water in Mexico is the San Pedro River which was found to be contaminated by MDR E. coli with a prevalence rate of 30.6\% [27]. In a study of Chigor et al. [26], surface waters used for irrigation in Zaria, Nigeria were found to be contaminated with pathogenic E. coli O157:H7, which are also MDR. While pathogenic E. coli strains were not identified in our study, our results nevertheless contribute to the growing body of evidence showing that irrigation waters serve as reservoirs of MDR bacteria. Curiously, there are certain patterns of antibiotic resistance that are common to $E$. coli isolates obtained from three different samples and from two different samples, such as water and soil isolates and water and vegetable isolates. One plausible explanation for this observation is the horizontal transmission of antibiotic resistant and MDR E. coli across the samples. Taken together, these results indicate that highly-polluted surface waters used for irrigation in selected urban farms in Metro Manila, Philippines harbor antibiotic-resistant and MDR E. coli.

The emergence of antibiotic resistance in aquatic environments, such as surface waters, and its subsequent dissemination has been widely documented [13-15,34]. Antibiotics of various origins enter aquatic milieus through different routes. As most antibiotics are poorly metabolized and absorbed by the body [35-39], antibiotic residues used in clinical and domestic settings are released from patients' urine and feces and discharged as wastewater effluents [36]. Similarly, outdated antibiotic remainders used in domestic settings are disposed of deliberately in household drains [16]. Meanwhile, antibiotics used in poultry and livestock domestication are released from animals' urine and feces and combine with agricultural runoffs that are usually introduced in nearby aquatic systems, such as surface waters and wastewater treatment plants $[16,17,37]$. Likewise, antibiotics used in aquaculture are deliberately introduced as feed additives into aquatic farms.

Although these antibiotics are usually diluted and degraded in aquatic environments, resulting to relatively low concentrations, they may act as regulatory substances and signaling molecules in bacteria [18]. In addition, trace and sub-inhibitory concentrations of antibiotics create a mutant selection window that significantly increases the tolerance of bacteria to antibiotics and potentially promotes and preserves antibiotic resistant bacteria through adaptive mutations. Consequently, antibiotic resistance can be acquired by other bacteria in aquatic environments through horizontal gene transfers, such as conjugation, transduction, and transformation. 
In urban agricultural farms of Metro Manila, Philippines, irrigation waters are typically derived from small bodies of water that are linked to Pasig River, Laguna Lake, and Manila Bay, which form a complex water system within Metro Manila [39]. Interestingly, these aquatic environments are contaminated by antibiotic residues of sulfamethoxazole, sulfamethazine, trimethoprim, and lincomycin that are presumably derived from human and animal use. Additionally, sulfamethoxazole-resistant genes, such as sul1, sul2, and sul3, were also observed [18]. The antibiotic residues found in water systems of Metro Manila are also detected in major rivers of China and Vietnam [18].

The application of these waters for irrigation purposes raises public health concern as they may potentially contaminate and disseminate antibiotic-resistant and multidrug resistant $E$. coli in the primary production environment, such as agricultural soils and fresh produce [26,28]. The presence of antibiotic resistant and MDR E. coli in fresh produce exposes humans to serious health hazards as there are vegetables that do not undergo microbial inactivation or preservation treatment prior to consumption $[6,29]$. Further, washing of vegetables does not completely eliminate the presence of these bacteria as they can be internalized in natural apertures of the vegetables, such as stomata, or localized in artificial crevices, cracks, and cuts [40]. Eventually, consumption of contaminated fresh produce may potentially cause foodborne gastrointestinal infections in humans. With regard to different ESBL gene types, a number of recent investigations highlighted the emergence and prevalence of CTX-M ESBLs as the most common type worldwide [41]. Before considering this, however, it is important to take into account the shifts in prevalence of ESBL genes across recent years and decades. In the 1990s, TEM- and SHV-type ESBLs were the dominant ESBL types, most often encountered in K. pneumoniae in hospitals. In the following decade, E. coli began to be recognized as the main source of ESBLs, with an increase in CTX-M ESBLs being described and blaCTX-M genes being recognized [41]. Therefore, different ESBL types, while not currently prevalent, may occur in many different locations. It is not unexpected, however, that the obtained result of the blaTEM gene's prevalence contrasts with the reported prevalence of CTX-M ESBLs, since the dominant ESBL type may vary between countries [42].

In the Philippines, there have also been studies to characterize molecularly ESBLs found in different bacterial isolates. In a study by Cabrera and Rodriguez (2009) [43], SHV-12 was found to be the dominant ESBL in Enterobacteriaceae tested, with some isolates carrying blaTEM-1. A year after, another study found CTX-M ESBLs as the predominant type of ESBLs in 95\% of isolates of Enterobacteriaceae obtained from the same location, indicating a shift in ESBL genes similar to those in other countries [44]. Two further studies had a similar result, finding CTX-M ESBLs to be most prevalent in ESBL-producing bacteria and supporting the trend observed in many surveys [12,45]. Like other research, however, the above studies were focused on clinical isolates, and it appears that there is no data on ESBL-producing bacteria in environmental samples from surface waters in the Philippines. Hence, our study is the first to report the presence of ESBL-producing bacteria in surface waters used for irrigation in the Philippines.

The results of this study may circumstantially indicate horizontal transmission of antibioticresistant and MDR E. coli from irrigation water to agricultural soils and vegetables. However, the results need to be interpreted with caution, as there was an unequal distribution of the number of $E$. coli isolates from the samples used in this study. The results also cannot conclusively determine the occurrence and direction of lateral transfer of antibiotic resistant and MDR E. coli. Hence, the possibility that antibiotic resistant and MDR E. coli originated from other sources cannot be discounted. The presence of antibiotic-resistant and MDR E. coli in fresh produce may be naturally inherent in vegetables due to the ubiquity of antibiotic resistant bacteria $[4,35]$. It may also be due to some other contaminating sources, such as poor handling of fresh produce during cultivation, harvesting and marketing and unsanitary production equipment and conditions [2,4].

The results of this study were also limited by the absence of sequencing to identify the ESBL genes and by clonality testing to determine the genetic relatedness of $E$. coli isolates used in this study. Therefore, the molecular identification of ESBL genes and genetic association of E. coli isolates used in this study are areas that warrant further investigation. With these findings, it is important 
that awareness regarding antibiotic resistance and its generation is raised among the public and in healthcare settings. Release of contaminants into the environment should be controlled in order to prevent emergence of antibiotic resistances [11].

\section{Conclusions}

The findings of this study showed that highly-polluted surface waters used for irrigation in selected urban farms of Metro Manila, Philippines are contaminated with antibiotic-resistant and MDR E. coli. Soil and vegetables obtained from the sampling sites likewise contain antibiotic-resistant and MDR isolates, albeit to a lesser extent. Additionally, certain patterns of antibiotic resistance were common to isolates obtained from different samples. This provides circumstantial evidence that surface waters harbor antibiotic-resistant and MDR bacteria that may be transferred to the primary production environment when used for irrigation, and may potentially cause foodborne gastrointestinal infections. Further research is warranted to unequivocally establish the occurrence of the horizontal transmission of antibiotic-resistant and MDR E. coli across the samples.

Author Contributions: Enrico S. Zara, Cielo Emar M. Paraoan, Ma. Angela Z. Dimasupil, Joseth Jermaine M. Abello, and Iñigo Teodoro G. Santos performed the experiments, analyzed the data, and prepared the manuscript; and Pierangeli G. Vital and Windell L. Rivera conceptualized the study, headed the project, and were in charge of the preparation of the paper.

Acknowledgments: This work was supported by the Natural Sciences Research Institute, University of the Philippines Diliman and the Department of Agriculture-Bureau of Agricultural Research of the Philippine Government.

Conflicts of Interest: The authors declare no conflict of interest.

\section{References}

1. Steele, M.; Odumeru, J. Irrigation water as source of foodborne pathogens on fruit and vegetables. J. Food Prot. 2004, 67, 2839-2849. [CrossRef] [PubMed]

2. Garcia, B.C.B.; Dimasupil, M.A.Z.; Vital, P.G.; Widmer, K.W.; Rivera, W.L. Fecal contamination in irrigation water and microbial quality of vegetable primary production in urban farms of Metro Manila, Philippines. J. Environ. Sci. Health Part B 2015, 50, 734-743. [CrossRef] [PubMed]

3. Food and Agriculture Organization of the United Nations World Health Organization. Microbiological Hazards in Fresh Fruits and Vegetables-Microbiological Risks Assessment Series; Pre-Publication Version; FAO: Rome, Italy; WHO: Geneva, Switzerland, 2008.

4. Holvoet, K.; Sampers, I.; Callens, B.; Dewulf, J.; Uyttendaele, M. Moderate prevalence of antimicrobial resistance in Escherichia coli isolates from lettuce, irrigation water and soil. Appl. Environ. Microbiol. 2013, 79, 6677-6683. [CrossRef] [PubMed]

5. $\quad$ Blaustein, R.A.; Shelton, D.R.; Van Kessel, J.A.S.; Karns, J.S.; Stocker, M.D.; Pachepsky, Y.A. Irrigation waters and pipe-based biofilms as sources for antibiotic-resistant bacteria. Environ. Monit. Assess. 2015, 188, 1-12. [CrossRef] [PubMed]

6. Levy, S.B. Factors impacting on the problem of antibiotic resistance. J. Antimicrob. Chemother. 2002, 49, 25-30. [CrossRef] [PubMed]

7. Levy, S.B.; Marshall, B. Antibacterial resistance worldwide: Causes, challenges and responses. Nat. Med. 2004, 10, 122-129. [CrossRef] [PubMed]

8. Huddleston, J.R. Horizontal gene transfer in the human gastrointestinal tract: Potential spread of antibiotic resistance genes. Infect. Drug Resist. 2014, 7, 167-176. [CrossRef] [PubMed]

9. Cosgrove, S.E. The relationship between antimicrobial resistance and patient outcomes: Mortality, length of hospital stay, and health care costs. Clin. Infect. Dis. 2006, 42, S82-S89. [CrossRef] [PubMed]

10. Tissera, S.; Lee, S.M. Isolation of Extended Spectrum $\beta$-lactamase (ESBL) Producing Bacteria from Urban Surface Waters in Malaysia. Malays. J. Med. Sci. 2013, 20, 14-22. [PubMed]

11. Lucena, M.A.H.; Metillo, E.B.; Oclarit, J.M. Prevalence of CTX-M Extended Spectrum $\beta$-lactamase-producing Enterobacteriaceae at a Private Tertiary Hospital in Southern Philippines. Philipp. J. Sci. 2012, 141, 117-121. 
12. Cruz, M.C.; Bacani, C.S.; Mendoza, A.B.; Hedreyda, C.T. Evaluation of extended-spectrum beta-lactamase production in Escherichia coli clinical isolates from three hospitals in Luzon, Philippines. Philipp. Sci. Lett. 2014, 7, 438-444.

13. Schwartz, T.; Kohnen, W.; Jansen, B.; Obst, U. Detection of antibiotic-resistant bacteria and their resistance genes in wastewater, surface water, and drinking water biofilms. FEMS Microbiol. Ecol. 2003, 43, 325-335. [CrossRef] [PubMed]

14. Watkinson, A.J.; Micalizzi, G.B.; Graham, G.M.; Bates, J.B.; Costanzo, S.D. Antibiotic-resistant Escherichia coli in wastewaters, surface waters, and oysters from an urban riverine system. Appl. Environ. Microbiol. 2007, 73, 5667-5670. [CrossRef] [PubMed]

15. Borjesson, S. Antibiotic Resistance in Wastewater: Methicillin-Resistant Staphylococcus Aureus (MRSA) and Antibiotic Resistance Genes; LiU-Tryck: Linköping, Sweden, 2009; ISBN 978-91-7393-629-3.

16. Amaya, E.; Reyes, D.; Paniagua, M.; Calderon, S.; Rashid, M.U.; Colque, P.; Kuhn, I.; Mollby, R.; Weintraub, A.; Nord, C.E. Antibiotic resistance patterns of Escherichia coli isolates from different aquatic environmental sources in Leon, Nicaragua. Clin. Microbiol. Infect. 2012, 18, E347-E354. [CrossRef] [PubMed]

17. Carey, D.E.; McNamara, P.J. The impact of triclosan on the spread of antibiotic resistance in the environment. Front. Microbiol. 2014, 5, 780. [CrossRef] [PubMed]

18. Suzuki, S.; Ogo, M.; Miller, T.W.; Shimizu, A.; Takada, H.; Siringan, M.A.T. Who possesses drug resistance genes in the aquatic environment?: Sulfamethoxazole ( $\mathrm{smx}$ ) resistance genes among the bacterial community in water environment of Metro Manila, Philippines. Front. Microbiol. 2013, 4, 102. [CrossRef] [PubMed]

19. Campilan, D.; Boncodin, R.; de Guzman, C. Multi-Sectoral Initiatives for Urban Agriculture in Metro Manila, Philippines CIP Program Report 1999-2000; International Potato Center: Lima, Peru, 2001.

20. Coyle, M.B. Antimicrobial Susceptibility Testing; Manual; American Society for Microbiology Press: Washington, DC, USA, 2005.

21. Clinical and Laboratory Standards Institute. Performance Standards for Antimicrobial Susceptibility Testing; CLSI: Wayne, PA, USA, 2012; p. 188.

22. Jarlier, V.; Nicolas, M.H.; Fournier, G.; Philippon, A. Extended Broad-Spectrum $\beta$-Lactamases Conferring Transferable Resistance to Newer $\beta$-Lactam Agents in Enterobacteriaceae: Hospital Prevalence and Susceptibility Patterns. Rev. Infect. Dis. 1988, 10, 867-878. [CrossRef] [PubMed]

23. Dallenne, C.; Da Costa, A.; Decre, D.; Favier, C.; Arlet, G. Development of a set of multiplex PCR assays for the detection of genes encoding important $\beta$-lactamases in Enterobacteriaceae. J. Antimicrob. Chemother. 2010, 65, 490-495. [CrossRef] [PubMed]

24. Takahashi, H.; Kimura, B.; Tanaka, Y.; Shinozaki, J.; Suda, T.; Fujii, T. Real-time PCR and enrichment culture for sensitive detection and enumeration of Escherichia coli. J. Microbiol. Methods 2009, 79, 124-127. [CrossRef] [PubMed]

25. Roe, M.T.; Vega, E.; Pillai, S.D. Antimicrobial resistance markers of class 1 and class 2 integron-bearing Escherichia coli from irrigation water and sediments. Emerg. Infect. Dis. 2003, 9, 822-826. [CrossRef] [PubMed]

26. Chigor, V.N.; Umoh, V.J.; Smith, S.I.; Igbinosa, E.O.; Okoh, A.I. Multidrug resistance and plasmid patterns of Escherichia coli $\mathrm{O} 157$ and other E. coli isolated from diarrhoeal stools and surface waters from some selected sources in Zaria, Nigeria. Int. J. Environ. Res. Public Health 2010, 7, 3831-3841. [CrossRef] [PubMed]

27. Ramirez Castillo, F.Y.; Avelar Gonzalez, F.J.; Garneau, P.; Márquez Díaz, F.; Guerrero Barrera, A.L.; Harel, J. Presence of multidrug resistant pathogenic Escherichia coli in the San Pedro River located in the State of Aguascalientes, Mexico. Front. Microbiol. 2013, 4, 147. [CrossRef] [PubMed]

28. Lamprecht, C.; Romanis, M.; Huisamen, N.; Carinus, A.; Schoeman, N.; Gunnar, O.S.; Trevor, J.B. Escherichia coli with virulence factors and multidrug resistance in the Plankenburg River. S. Afr. J. Sci. 2014, 110, 1-6. [CrossRef]

29. Njage, P.M.K.; Buys, E.M. Pathogenic and commensal Escherichia coli from irrigation water show potential in transmission of extended spectrum and Ampc $\beta$-lactamases determinants to isolates from lettuce. Microb. Biotechnol. 2015, 8, 462-473. [CrossRef] [PubMed]

30. Paraoan, C.E.M.; Rivera, W.L.; Vital, P.G. Detection of Class I and II integrons for the assessment of antibiotic and multidrug resistance among Escherichia coli isolates from agricultural irrigation waters in Bulacan, Philippines. J. Environ. Sci. Health Part B 2017, 52, 306-313. [CrossRef] [PubMed]

31. Chopra, I.; Roberts, M. Tetracycline antibiotics: Mode of action, applications, molecular biology, and epidemiology of bacterial resistance. Microbiol. Mol. Biol. Rev. 2001, 65, 232-260. [CrossRef] [PubMed] 
32. Magiorakos, A.P.; Srinivasan, A.; Carey, R.B.; Carmeli, Y.; Falagas, M.E.; Giske, C.G.; Harbarth, S.; Hindler, J.F.; Kahlmeter, G.; Olsson-Liljequist, B. Multidrug-resistant, extensively drug-resistant and pandrug-resistant bacteria: An international expert proposal for interim standard definitions for acquired resistance. Clin. Microbiol. Infect. 2012, 18, 268-281. [CrossRef] [PubMed]

33. Shakya, P.; Barrett, P.; Diwan, V.; Marothi, Y.; Shah, H.; Chhari, N.; Tamhankar, A.J.; Pathak, A.; Lundborg, C.S. Antibiotic resistance among Escherichia coli isolates from stool samples of children aged 3 to 14 years from Ujjain, India. BMC Infect. Dis. 2013, 13, 1-6. [CrossRef] [PubMed]

34. Marti, E.; Variatza, E.; Balcazar, J.L. The role of aquatic ecosystems as reservoirs of antibiotic resistance. Trend Microbiol. 2013, 22, 36-41. [CrossRef] [PubMed]

35. Taylor, D.N. Poorly absorbed antibiotics for the treatment of traveler' diarrhea. Clin. Infect. Dis. 2005, 41, S564-S570. [CrossRef] [PubMed]

36. Diwan, V.; Tamhankar, A.J.; Khandal, R.K.; Sen, S.; Aggarwal, M.; Marothi, Y.; Iyer, R.V.; Sundblad-Tonderski, K.; Stalsby-Lundborg, C. Antibiotics and antibiotic-resistant bacteria in waters associated with a hospital in Ujjain, India. BMC Public Health 2010, 10, 414. [CrossRef] [PubMed]

37. Zhu, Y.G.; Johnson, T.A.; Su, J.Q.; Qiao, M.; Guo, G.X.; Stedtfeld, R.D.; Hashsham, S.A.; Tiedje, J.M. Diverse and abundant antibiotic resistance genes in chinese swine farms. Proc. Natl. Acad. Sci. USA 2013, 110, 3435-3440. [CrossRef] [PubMed]

38. Wang, Q.; Mao, D.; Mu, Q.; Luo, Y. Enhanced horizontal transfer of antibiotic resistance genes in freshwater microcosms induced by an ionic liquid. PLoS ONE 2015, 10, e0126784. [CrossRef] [PubMed]

39. UN Center for Human Settlements. Guidelines for Settlement Planning in Areas Prone to Flood Disasters; United Nations Center for Human Settlements: Nairobi, Kenya, 1995.

40. Sela, S.; Manulis-Sasson, S. What else can we do to mitigate contamination of fresh produce by foodborne pathogens? Microb. Biotechnol. 2015, 8, 29-31. [CrossRef] [PubMed]

41. Canton, R.; Coque, T.M. The CTX-M $\beta$-lactamase pandemic. Curr. Opin. Microbiol. 2006, 9, 466-475. [CrossRef] [PubMed]

42. Hawkey, P.M. Prevalence and clonality of extended-spectrum $\beta$-lactamases in Asia. Clin. Microbiol. Infect. 2008, 14, 159-165. [CrossRef] [PubMed]

43. Cabrera, E.C.; Rodriguez, R.D. First report on the occurrence of SHV-12 extended-spectrum beta-lactamaseproducing Enterobacteriaceae in the Philippines. J. Microbiol. Immunol. Infect. 2009, 42, 74-85. [PubMed]

44. Tian, G.; Garcia, J.; Adams-Haduch, J.M.; Evangelista, J.P.; Destura, R.V.; Wang, H.; Doi, Y. CTX-M as the predominant extended-spectrum $\beta$-lactamases among Enterobacteriaceae in Manila, Philippines. J. Antimicrob. Chemother. 2010, 65, 584-586. [CrossRef] [PubMed]

45. Kanamori, H.; Navarro, R.B.; Yano, H.; Sombrero, L.T.; Capeding, M.R.Z.; Lupisan, S.P.; Olveda, R.M.; Arai, K.; Kunishima, H.; Hirakata, Y.; et al. Molecular characteristics of extended-spectrum $\beta$-lactamases in clinical isolates of Enterobacteriaceae from the Philippines. Acta Trop. 2011, 120, 140-145. [CrossRef] [PubMed]

(C) 2018 by the authors. Licensee MDPI, Basel, Switzerland. This article is an open access article distributed under the terms and conditions of the Creative Commons Attribution (CC BY) license (http:// creativecommons.org/licenses/by/4.0/). 